\title{
Material Application of a Transformer Box: A Study on the Electromagnetic Shielding Characteristics of Al-Ta Coating Film with Plasma-Spray Process
}

\author{
Fei-Shuo Hung \\ Department of Leisure, Recreation and Tourism Management, Southern Taiwan University of Science and \\ Technology, Tainan 701, Taiwan; fshung@stust.edu.tw; Tel.: +886-6-253-3131 (ext. 8292) \\ Received: 10 July 2019; Accepted: 1 August 2019; Published: 6 August 2019

\begin{abstract}
In this study we present the results of two experiments. In the first one, a Ta-Al-SS (stainless steel (SS)) multilayer coating structure was prepared using plasma spraying equipment to investigate the coating structure and interface properties. In the second one, $\mathrm{Ta}-\mathrm{Al}$ on multilayer glass was prepared using the sputtering process to measure the thickness effect of thin film on electromagnetic wave shielding (EMI) characteristics and on the design of high-power switchboard covers. According to the experimental results, the multilayer structure of Ta-Al on SS improves the mechanical properties of a stainless steel plate by enhancing the explosion-proof property. An appropriate thickness of the plasma-sprayed pure aluminum layer can increase the adhesion to the stainless steel substrate and buffer the stress effect. After heat treatment (annealing), the Ta-Al-SS multilayer structural characteristics are excellent and suitable for shielding effects at different temperatures and humidity, which can be used as a reference for the engineering application of communication rooms and base power stations. According to EMI test of multi-coated glass (Ta-Al-glass), by increasing the thickness of Ta layer, we cannot effectively improve full-frequency EMI shielding with improved shielding at low-mid frequency condition. In addition, the Ta-Al interface formation of an $\mathrm{Al}-\mathrm{Ta}-\mathrm{O}$ compound layer can improve the adiabatic effect to reduce the thermal conductivity.
\end{abstract}

Keywords: Al-Ta; coating; electromagnetic interference; plasma spraying; sputtered; annealing

\section{Introduction}

Electromagnetic interference (EMI) is a new type of pollution that has been discovered in recent decades. The Bioelectrochemistry Journal indicated that electromagnetic waves of over $50 \mathrm{~Hz}$ will cause damage and variations to the human body's DNA structure. The high-density residential environment of Taiwan contains many switchboards [1,2]. It is worth noting that switchboard covers are made of iron, and the internal layer of switchboards are also made of iron, copper wire and insulating oil [3-7]. Switchboard covers must contain a strong electromagnetic field, and be fire- and explosion-proof [8-10]. The ideal electromagnetic shielding material must effectively protect from strong electromagnetic variable fields, have a light weight, thin thickness and strong mechanical properties [11-13].

Moreover, the shielding has to be adapted to various environmental conditions, such as high temperature resistance, high pressure resistance, rust resistance, dust resistance, high explosion resistance and electrical conductivity [14-17]. Up to now, many research teams have been actively exploring various shielding methods. In all the shielding methods, the surface treatment methods, such as conductive film [18,19] and conductive powder [20-24], have had better shielding effects. However, they are easy to wear, peel, oxidize, difficult to process and expensive, etc. Therefore, the coating effect is reduced by aging. Previous studies found that Ta and Al have excellent EMI shielding. By following them, in these current studies we found that the plasma coating of a stainless-steel 
plate (304 SS) with a Ta/Al multilayer enhances heat-resistant, explosion-proof, and electromagnetic waves shielding performance. To better understand the quality and interface characteristics of the coating multilayer, we investigated a Ta-Al multilayer structure on glass to evaluate the EMI shielding. Our results can be a straightforward guide to the design of switchboard covers, and be a reference for EMI engineering applications in equipment rooms, high power stations, and medical institutions.

\section{Experimental Procedure}

\subsection{Plasma Spraying Ta/Al/SS Multilayer Structure Preparation}

Aluminum ( $\mathrm{Al})$ and tantalum (Ta) have excellent EMI electromagnetic shielding efficacy. In this study, a $1 \mathrm{~mm}$ thick 304 stainless steel (SS) was used as the matrix, then $\mathrm{Al}$ and Ta layers were separately sprayed to form a sandwich structure. The thickness of the coating was controlled into $\mathrm{Al}(100 \mu \mathrm{m})$ and $\mathrm{Ta}(200,400$, and $600 \mu \mathrm{m})$. In the experiment, first the 304 stainless steel was cleaned, then divided into two stages. The first stage: spray Al layer with argon plasma. The second stage: spray Ta layer with argon plasma to complete the $\mathrm{Ta} / \mathrm{Al} / 304 \mathrm{SS}$ sandwich structure. The spraying was conducted in the plasma spraying room to avoid oxidation of the spray metal-layer; this metal spraying technology (cathode: tungsten) is already commercially very mature.

The scanning electron microscopy with energy dispersive spectroscopy (SEM-EDS, JEOL JIB-4601F, Tokyo, Japan), thermal conductivity meter (TLS-100, TechMax, Daejeon, Korea; QTM-710, KEM, Kyoto, Japan), sprayer, dry ice, alcohol, and linear dilatometer (JIN-BOMB 800 Nikon Eclipse, Kaohsiung, Taiwan) to calculate the thermal expansion coefficient (thermogravimetric analysis and simultaneous difference thermal analysis (TMA/SDTA)), etc., were used in this experiment to analyze the coating surface characteristics, film thickness effect, and interface characteristics. Afterward, tensile testing was conducted on the Ta-Al-SS multilayer structure in order to evaluate the explosion-proof performance; and the thermal conductivity of the overall system was also measured in order to evaluate the heat insulation.

\subsection{Electromagnetic Wave Shielding Test}

In this study, the Ta-Al-glass multilayer structures were prepared for EMI shielding review. The Ta-Al multilayer structures on glass were exclusively prepared to investigate the EMI shielding. The thickness of the coating was set to $\mathrm{Al}(50 \mathrm{~nm}), \mathrm{Ta}(100,200$, and $400 \mathrm{~nm})$. In addition, this study investigated the EMI shielding effect of multilayer structures under different environmental factors. Four experimental systems were performed: (1) $\mathrm{Al}(50 \mathrm{~nm})+\mathrm{Ta}\left(200 \mathrm{~nm} / 25^{\circ} \mathrm{C}\right.$, Relative Humidity $=$ $50 \%) ;(2) \mathrm{Al}(50 \mathrm{~nm})+\mathrm{Ta}\left(200 \mathrm{~nm} /-40{ }^{\circ} \mathrm{C}\right.$, Relative Humidity $\left.=0 \%\right) ;(3) \mathrm{Al}(50 \mathrm{~nm})+\left(200 \mathrm{~nm} / 25^{\circ} \mathrm{C}\right.$, Relative Humidity $=100 \%)$; and $(4) \mathrm{Al}(50 \mathrm{~nm})+\mathrm{Ta}\left(200 \mathrm{~nm} / 100{ }^{\circ} \mathrm{C}\right.$, Relative Humidity $\left.=100 \%\right)$. In addition, the $\mathrm{Al}(50 \mathrm{~nm})+\mathrm{Ta}(200 \mathrm{~nm})$ system was annealed at 200,300 and $400{ }^{\circ} \mathrm{C}$ for $1 \mathrm{~h}$ in a vacuum (designated as $\mathrm{Al}-\mathrm{Ta}-\mathrm{H}$ ) to clarify the relationship between interface characteristics and EMI frequency. The coaxial electromagnetic wave shielding effect tester (Elgal set 19A coaxial holder, TES, Taipei, Taiwan) was used with scanning frequency range from $300 \mathrm{~K}$ to $3 \mathrm{GHz}$ and accuracy of $\pm 10 \mathrm{ppm}$. Normal incident plane waves were used. The measured frequency range was controlled in the range from 50 to $3000 \mathrm{MHz}$. All the results were averaged in 3-5 points of data. Finally, the shielding efficiency value was obtained by automatic calculation [25].

\section{Results and Discussion}

Figure 1 shows the characteristics of the $\mathrm{Al}$ layer being uneven morphology and irregular surface roughness. It was found that the oxidized aluminum structure was formed on the surface of the aluminum layer and, as expected, we found that the aluminum self-passivated to aluminum oxide (Figures 1-3). Therefore, the thermal expansion coefficient of the sprayed aluminum layer was measured to be $12.5 \times 10^{-6}{ }^{\circ} \mathrm{C}^{-1}$ and the thermal conductivity at the surface of the aluminum layer was $62 \mathrm{~W} \mathrm{~m}^{-1} \mathrm{~K}^{-1}$. The result of it is good for the heat insulation effect. 


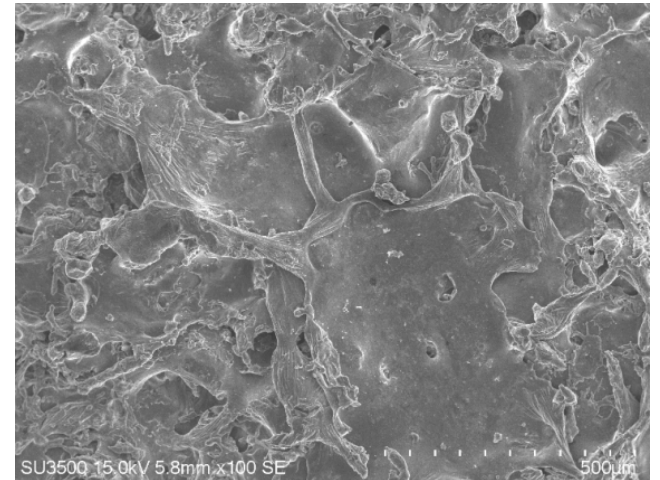

(a)

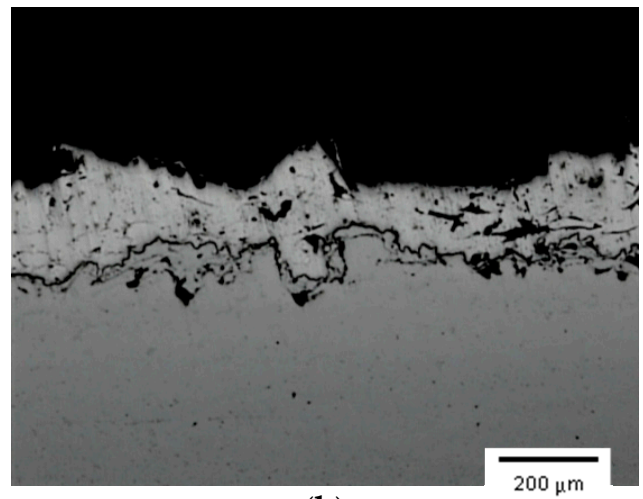

(b)

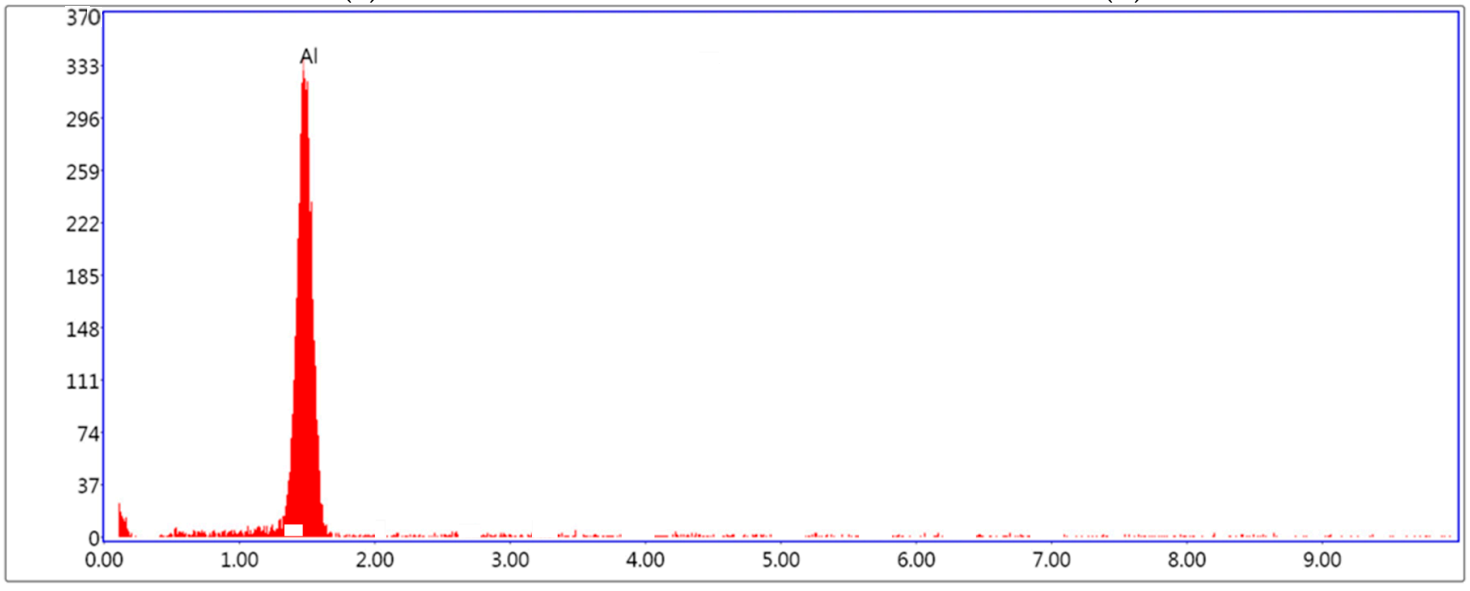

Lsec: $30.0 \quad 1$ Cnts $1.750 \mathrm{keV} \quad$ Det: Octane Plus Det

eZAF Smart Quant Results

\begin{tabular}{c|c|c|c|c|c|c|c|c|c}
\multicolumn{2}{c}{ Element Weight \%Atomic \% Net Int. } & \multicolumn{1}{c}{ Error \% } & Kratio & Z & R & A \\
\hline O K & 4.07 & $6 . .67$ & 1.61 & 51.00 & 0.0145 & 1.1254 & 0.9600 & 0.31699 & 1.0000 \\
\hline AlK & 95.93 & 93.33 & 149.13 & 3.13 & 0.9387 & 0.9944 & 1.0015 & 0.9826 & 1.0013 \\
\hline
\end{tabular}

(c)

Figure 1. The surface characteristic of plasma-sprayed Al (a) surface and (b) subsurface; (c) The surface characteristics of energy dispersive X-ray spectroscopy (EDX).

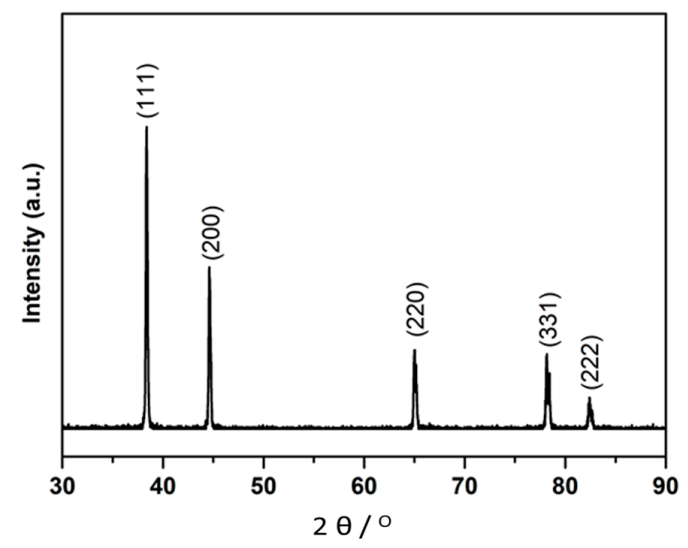

Figure 2. X-ray diffraction (XRD) of plasma-sprayed Al layer.

Figure 3 shows the surface of the plasma-sprayed Ta-Al-SS multilayer structure. According to Figure 3, it was found that the sandwich structures were still visible (Figure 3a) when the thickness of the aluminum coating was fixed at $100 \mu \mathrm{m}$ and the thickness of the tantalum layer was increased to $400 \mu \mathrm{m}$. 
However, the Ta layer peeled when the thickness of it was increased to $600 \mu \mathrm{m}$. The main reason for the peeling occurring is that the relative bonding strength was not provided on the underlying aluminum layer because the shrinkage stress was too strong (the arrow in Figure $3 \mathrm{~b}$ points to the peeling crack).

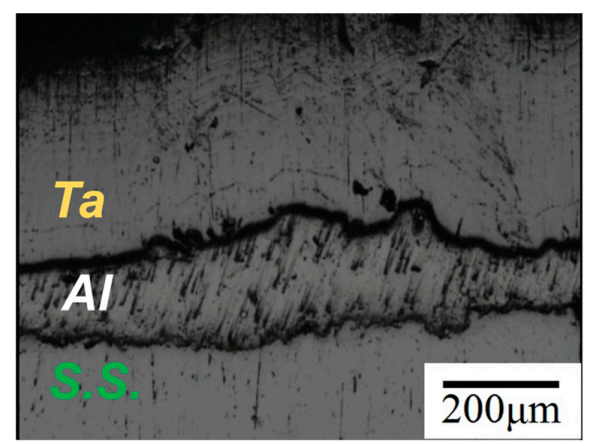

(a)

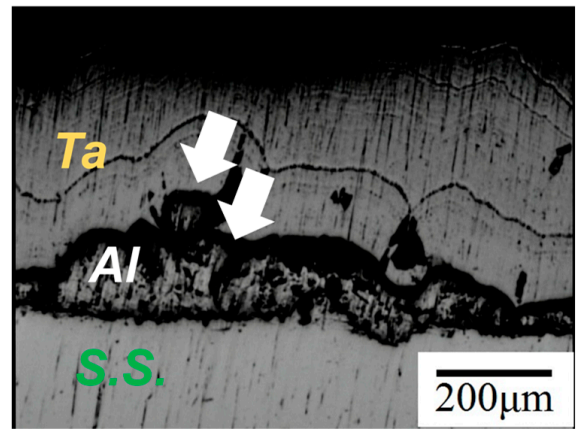

(b)

Figure 3. The surface characteristic of the multilayer structure of plasma-sprayed Ta-Al-SS: (a) Ta $(400 \mu \mathrm{m}) / \mathrm{Al}(100 \mu \mathrm{m}) / \mathrm{SS} ;(\mathbf{b}) \mathrm{Ta}(600 \mu \mathrm{m}) / \mathrm{Al}(100 \mu \mathrm{m}) / \mathrm{SS}$.

The tensile test of the test piece (Figure 4) in this experiment, it was found that the strength of pure 304 stainless steel was about $460 \mathrm{MPa}$ and that of the Ta $(400 \mu \mathrm{m}) / \mathrm{Al}(100 \mu \mathrm{m}) / \mathrm{SS}$ test piece was increased to $550 \mathrm{MPa}$. Based on this result, the improvement of the explosion-proof capability of the experimental material was indicated.

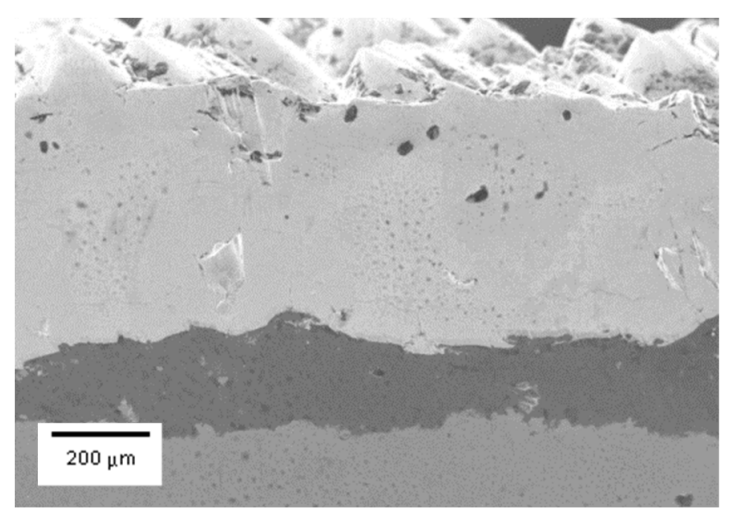

(a)

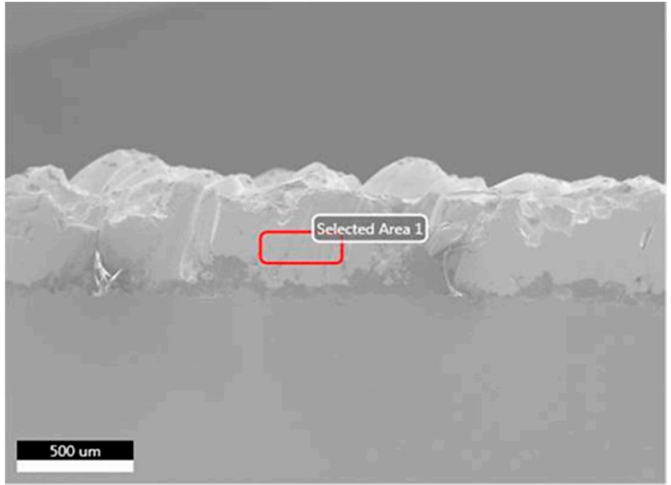

(b)

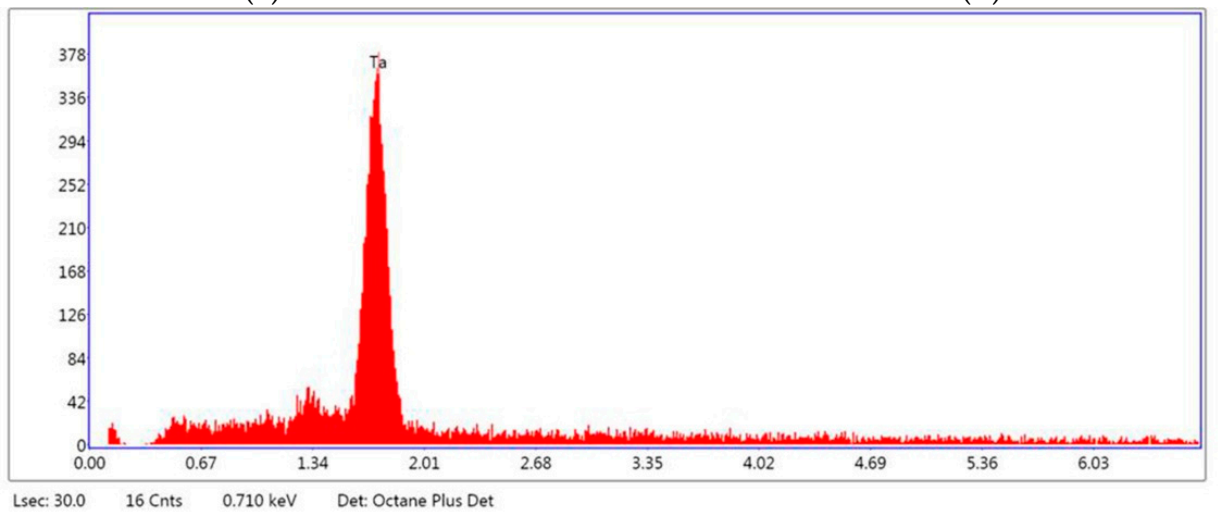

(c)

Figure 4. Ta $(400 \mu \mathrm{m}) / \mathrm{Al}(100 \mu \mathrm{m}) / \mathrm{SS}$ test piece: Shows the cross-section characteristics of the plasma-sprayed Ta-Al-SS test piece, whereby it can be found that each interface is completely attached, and, with the help of SEM/EDX, it was confirmed that the top layer of the Ta film is $100 \%$ pure metal. (a) Subsurface interface characteristics, (b,c) EDX analysis of Ta layer. 
The Al-Ta-O compound, which was formed at the Ta-Al interface, was confirmed by performing $\mathrm{Ta} / \mathrm{Al}$ interface EDX analysis (Figure 5) on the Figure 3 specimen with the tantalum layer removed. The existence of this compound layer has two functions. First, improving the bonding strength of the Ta-Al interface, so that the Ta layer does not shed or peel easily. Second, forming a high-resistance compound layer, which can improve the heat insulation effect and reduce the total conductivity. The thermal expansion coefficient of the Al-Ta-O compound layer was $4.8 \times 10^{-6}{ }^{\circ} \mathrm{C}^{-1}$ and the thermal conductivity was $42 \mathrm{~W} \mathrm{~m}^{-1} \mathrm{~K}^{-1}$, thus the resulting thermal insulation effect of the overall system was definitely improved.

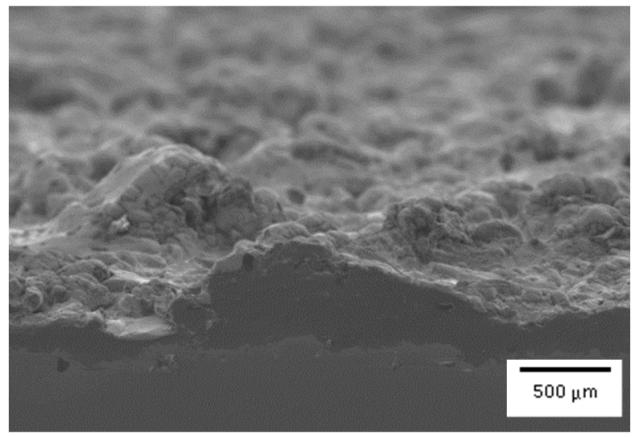

(a)

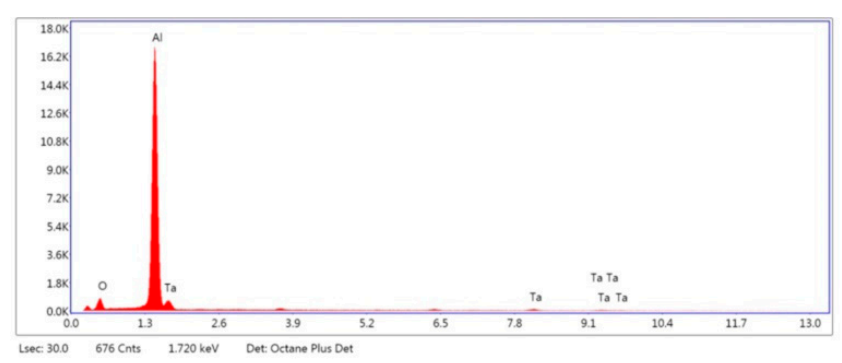

(b)

Figure 5. Ta $(400 \mu \mathrm{m}) / \mathrm{Al}(100 \mu \mathrm{m}) / \mathrm{SS}$ test piece: (a) surface characteristics of residual Al layer; (b) EDX analysis of $\mathrm{Al}-\mathrm{Ta}-\mathrm{O}$ compound layer.

For the Ta-Al-glass system, the EMI shielding was significantly promoted when the thickness of the Ta film was increased from 100 and 200 to $400 \mathrm{~nm}$ (Figure 6). In other words, increasing the Ta film thickness not only increased the index of crystallinity (IOC) and the low resistivity (Table 1), but also enhanced the electromagnetic shielding effect. Otherwise, according to the data of 200 and $400 \mathrm{~nm}$, it was found that there was linear relationship between EMI shielding at low and middle frequencies.

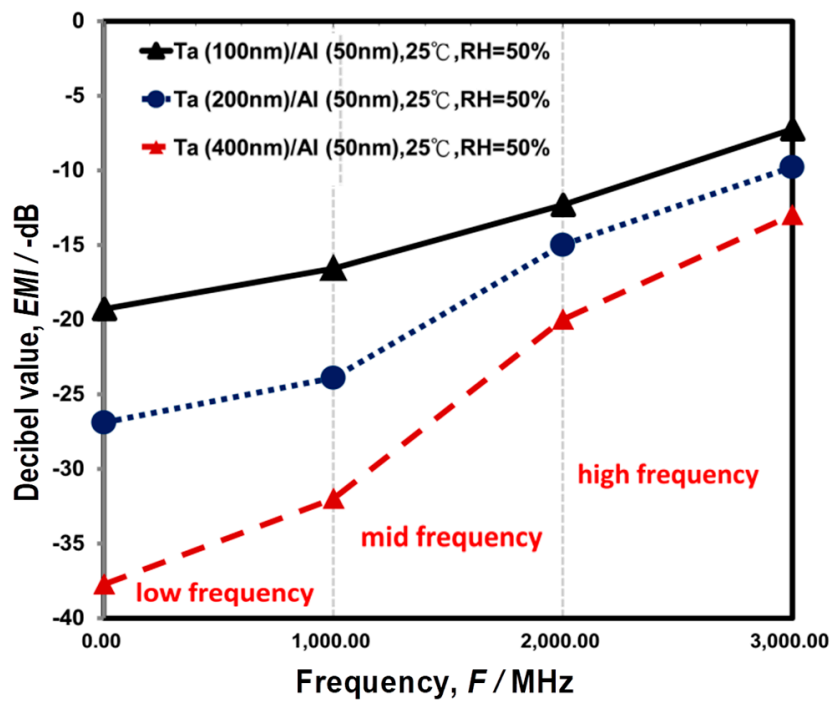

Figure 6. EMI shielding of $\mathrm{Ta} / \mathrm{Al} /$ glass test sample with different Ta thicknesses.

Table 1. Four-point probe result of Ta $(100 \mathrm{~nm}) / \mathrm{Al}(50 \mathrm{~nm}) /$ glass $(\Omega \mathrm{m})$.

\begin{tabular}{cc}
\hline Specimen & Resistivity \\
\hline $\mathrm{Ta}(100 \mathrm{~nm}) / \mathrm{Al}(50 \mathrm{~nm})$ & $68.07 \times 10^{-8}$ \\
$\mathrm{Ta}(200 \mathrm{~nm}) / \mathrm{Al}(50 \mathrm{~nm})$ & $52.38 \times 10^{-8}$ \\
$\mathrm{Ta}(400 \mathrm{~nm}) / \mathrm{Al}(50 \mathrm{~nm})$ & $26.82 \times 10^{-8}$ \\
\hline
\end{tabular}


This study designed four systems of different temperatures and humidities and investigated the EMI shielding effect of the multilayer Ta/Al/glass structure. The experimental results show that under the influence of different thicknesses of Ta film, the EMI shielding had obvious promotion effects and a linear relationship (Figure 7). When the thickness of the Ta film does not change (controlled at $200 \mathrm{~nm}$ ), the temperature test results showed that the EMI shielding increased with increasing temperature (Figure 8).

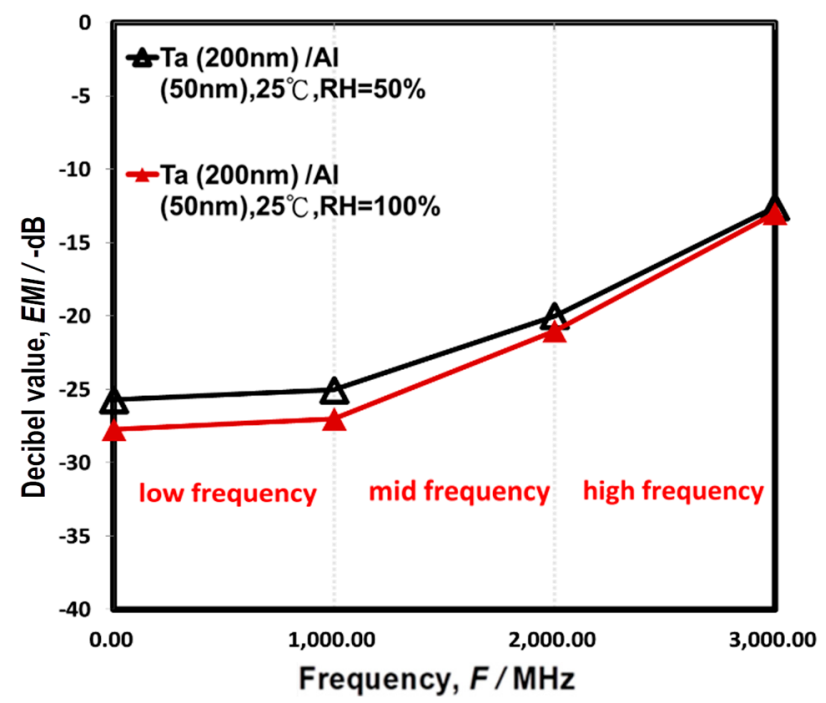

Figure 7. EMI shielding of Ta/Al/glass test sample with different humidities.

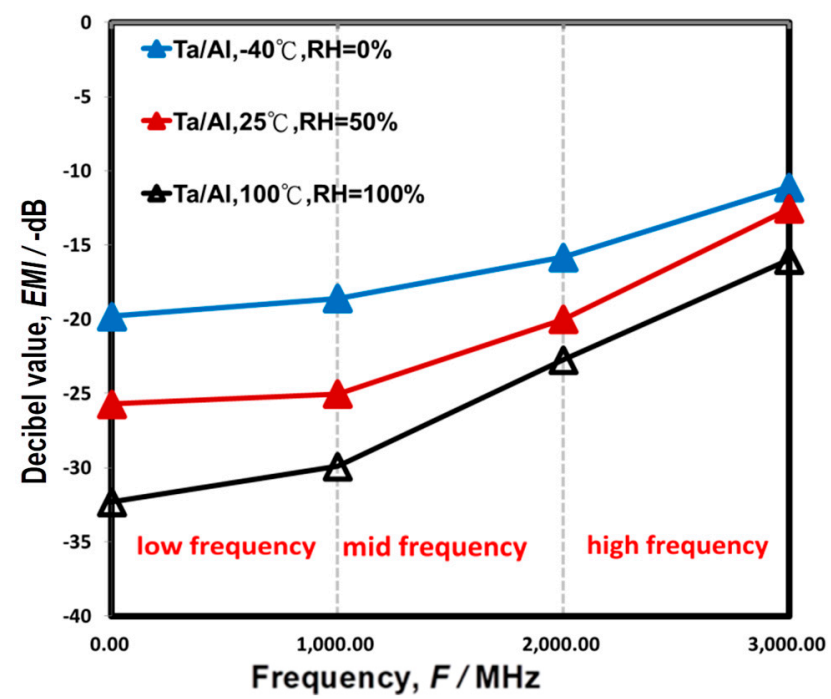

Figure 8. EMI shielding of Ta $(200 \mathrm{~nm}) / \mathrm{Al}(50 \mathrm{~nm}) /$ glass samples with different temperatures and humidity.

In addition, the interface effect was caused by the porosity increasing or the formation of interface microcracks when Ta film thickness was increased. This resulted in the inability of the electromagnetic shielding efficacy to be improved at high frequency; and increasing temperature and humidity had obvious benefits on electromagnetic shielding. Therefore, in terms of overall performance, the Ta $(200 \mathrm{~nm}) / \mathrm{Al}(50 \mathrm{~nm}) /$ glass structure not only improved the conductivity (Table 1), but also enhanced the low-middle-frequency EMI shielding.

To understand the mechanism of EMI shielding, EDS analysis was used. Based on this analysis, the Al-Ta-O layer could contribute to the bonding strength and thermal insulation effect. Additionally, it also had obvious benefits in low-middle-frequency shielding. However, the shielding effect had 
no significant difference in high-frequency shielding. Notably, increasing the thickness of the Ta layer might promote the growth of the Al-Ta-O layer, thus the thickness of the Ta layer should be controlled below $200 \mathrm{~nm}$ to avoid the interface peeling. If the thickness of the Ta layer is continuously increased, it will limit the contribution to the substantial EMI system. This study chose a Ta $(200 \mathrm{~nm}) / \mathrm{Al}$ $(50 \mathrm{~nm}) /$ glass structure to perform the heat-treatment to obtain the annealing structure $(200,300$, and $400{ }^{\circ} \mathrm{C}$ ). The annealing induced a phase transformation at the interface, resulting in an inverse change at different frequencies. In Figure 9, the annealing treatment not only promotes the contribution of the Al-Ta-O layer, but also improves the higher frequency EMI shielding. It is worth noting that for commercial use, cost competitiveness, and application, the electromagnetic shielding effect (SE) of the $\mathrm{Ta}(200 \mathrm{~nm}) / \mathrm{Al}(50 \mathrm{~nm}) / \mathrm{glass}$ structure had a good level of shielding effect above SE $>25 \mathrm{~dB}$.

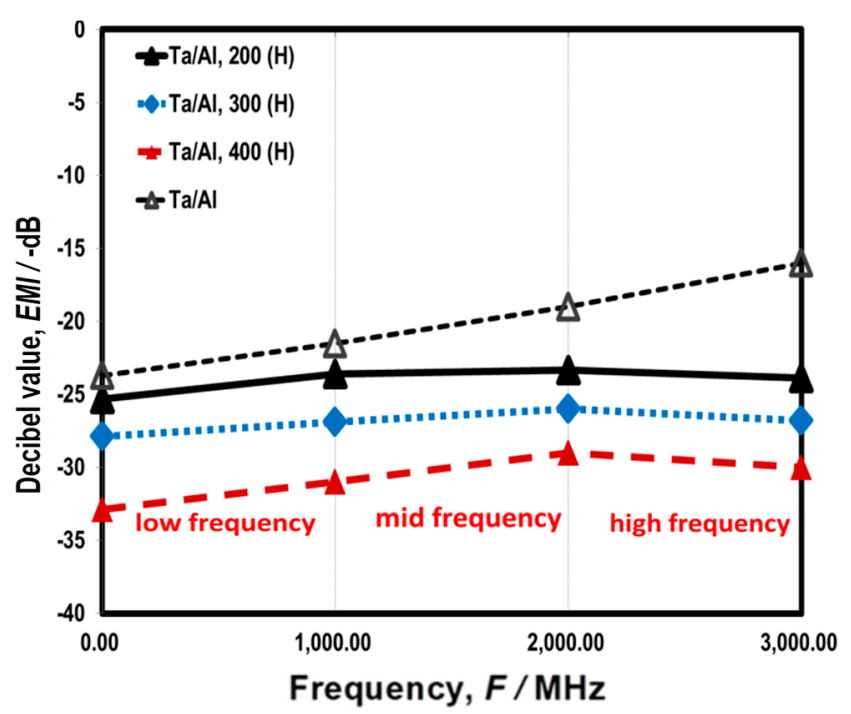

Figure 9. EMI shielding characteristics of un-annealed and annealed specimens: Ta (200 nm)/Al $(50 \mathrm{~nm}) /$ glass, $25^{\circ} \mathrm{C}, \mathrm{RH}=50 \%$.

\section{Conclusions}

- $\quad \mathrm{The} \mathrm{Ta} / \mathrm{Al} / \mathrm{SS}$ multilayer structure can improve the mechanical properties and interfacial adhesion of stainless steel plates. The Al-Ta-O compound layer interface can improve the thermal insulation effect and reduce the thermal conductivity, which were confirmed to achieve explosion-proof and heat-resisting effects.

- Increasing the Ta layer thickness can improve EMI shielding effectively at low and middle frequency conditions. For the $\mathrm{Ta}(200 \mathrm{~nm}) / \mathrm{Al}(50 \mathrm{~nm})$ structure, EMI shielding increased with increasing temperature. After annealing, it had significant positive effects at high-frequency condition.

Funding: This research was supported by the Ministry of Science and Technology of Taiwan, ROC (Contract No. MOST 107-2622-E-218-007-CC3).

Acknowledgments: The author is grateful to the Department of Leisure, Recreation and Tourism Management, Southern Taiwan University of Science and Technology for the support of this research.

Conflicts of Interest: The author declares no conflict of interest.

\section{References}

1. Chiang, C.M.; Lai, C.M. A study on the comprehensive indicator of indoor environment assessment for occupants' health in Taiwan. Build. Environ. 2002, 37, 387-392. [CrossRef]

2. Wang, C.; $\mathrm{Wu}, \mathrm{T}$. $\mathrm{TiO}_{2}$ nanoparticles with efficient photocatalytic activity towards gaseous benzene degradation. Ceram. Int. 2015, 41, 2836-2839. [CrossRef] 
3. Hung, F.S. Adding effects of Ni and Mn on electromagnetic interference (EMI) shield of Sn-based architectural materials. Trans. Nonferrous Met. Soc. China 2013, 23, 2633-2637. [CrossRef]

4. Liu, H.Y.; Sun, W.C.; Wei, S.Y.; Yu, S.M. Characterization of $\mathrm{TiO}_{2}$-based MISIM ultraviolet photodetectors by ultrasonic spray pyrolysis. IEEE Photonics Technol. Lett. 2016, 28, 637-640. [CrossRef]

5. Liu, D.; Deng, S. The study of metal meshes on electromagnetic interference shielding effectiveness. In Proceedings of the Asia-Pacific Conference on Environmental Electromagnetics, Shanghai, China, 7 May 2000; pp. 326-332.

6. Liboff, A.R. Geomagnetic cyclotron resonance in living cells. J. Biolog. Phys. 1985, 13, 99-102. [CrossRef]

7. Liu, J.C.; Ho, S.S.; Bor, S.S.; Lu, P.C. Tchebyshev approximation method for Salisbury screen design. IEE Proc. H Microwav. Antennas Propag. 1993, 140, 414-416. [CrossRef]

8. Mcleod, B.R.; Liboff, A.R. Dynamic characteristics of membrane ions in multifield configurations of low-frequency electromagnetic radiation. Bioelectromagnetics 1986, 7, 177-189. [CrossRef]

9. Merchant, C.J.; Renew, D.C.; Swanson, J. Exposures to power frequency magnetic field in the home. J. Radiol. Prot. 1994, 14, 77-87. [CrossRef]

10. Wu, C.H.; Hung, F.Y.; Lui, T.S.; Chen, L.H. Microstructural characteristics and the charge-discharge characteristics of $\mathrm{Sn}-\mathrm{Cu}$ thin film materials. Mater. Trans. 2009, 50, 381-387. [CrossRef]

11. Tenforde, T.S.; Kaune, W.T. Interaction of extremely low frequency electric and magnetic fields with humans. Health Phys. 1987, 53, 585-606. [CrossRef]

12. Ubeda, A.; Leaf, J.; Trillo, M.A.; Jimenez, M.A.; Delgado, J.M. Pulse shape of magnetic fields influences chick embryogenesis. J. Anat. 1982, 37, 513-536.

13. Vossen, J.L. Transparent Conducting Films. In Physics of Thin Films; Hass, G., Francombe, M.H., Hoffman, R.W., Eds.; Academic Press: New York, NY, USA, 1977; pp. 1-71.

14. Wenderoth, K.; Petermann, J. Synergism on electromagnetic inductance (EMI)-shielding in metal- and ferroelectric-particle filled polymers. Polym. Composite 1989, 10, 52-56. [CrossRef]

15. Wertheimer, N.; Leeper, E. Electrical wiring configurations and childhood cancer. Am. J. Epidemiol. 1979, 109, 273-284. [CrossRef] [PubMed]

16. Wang, T.; Chen, G.; Wu, C.; Wu, D. Study on the graphite nanosheets/resin shielding coatings. Prog. Org. Coat. 2007, 59, 101-105. [CrossRef]

17. Vardelle, A.; Vardelle, M.; Fauchais, P. Influence of velocity and surface temperature of alumina particles on the properties of plasma-sprayed coatings. Plasma Chem. Plasma Process. 1982, 2, 255-291. [CrossRef]

18. Yu, D.Q.; Xie, H.P.; Wang, L. Investigation of interfacial microstructure and wetting property of newly developed Sn-Zn-Cu solders with Cu substrate. J. Alloy. Compd. 2004, 385, 119-125. [CrossRef]

19. Faria, D.R.; Vieira, M.; Faria, F.C.; Premebida, C. Affective facial expressions recognition for human-robot interaction. In Proceedings of the 2017 26th IEEE International Symposium on Robot and Human Interactive Communication (RO-MAN), Lisbon, Portugal, 28 August-1 September 2017; pp. 805-810.

20. Perini, K.; Ottele, M.; Fraaij, A.L.A.; Haas, E.M.; Raiteri, R. Vertical greening systems and the effect on air flow and temperature on the building envelope. Build. Environ. 2011, 46, 2287-2294. [CrossRef]

21. Barroca, N.; Borges, L.M.; Velez, F.J.; Monteiro, F.; Górski, M.; Castro-Gomes, J. Wireless sensor networks for temperature and humidity monitoring within concrete structures. Constr. Build. Mater. 2013, 40, 1156-1166. [CrossRef]

22. Hung, F.S.; Hung, F.Y.; Chiang, C.M. Crystallization and annealing effects of sputtered tin alloy films on electromagnetic interference shielding. Appl. Surf. Sci. 2011, 257, 3733-3738. [CrossRef]

23. Juan, P.R.; Camacho, N.; Barberis, E.; Palma, S.D. Challenges and opportunities related to health promotion in community pharmacies: Obstacles and professional perspectives. J. 3D Print. Med. 2018, 2, 313-320.

24. Hung, F.S.; Hung, F.Y.; Chiang, C.M.; Lui, T.S. Electromagnetic interference shielding characteristics of Sn-Al powder coating layers. Mater. Trans. 2008, 49, 655-660. [CrossRef]

25. Tipler, P.A.; Mosca, G. Physics for Scientists and Engineers: Electricity, Magnetism, Light, and Elementary Modern Physics, 5th ed.; W.H. Freeman: London, UK, 2003.

(C) 2019 by the author. Licensee MDPI, Basel, Switzerland. This article is an open access article distributed under the terms and conditions of the Creative Commons Attribution (CC BY) license (http://creativecommons.org/licenses/by/4.0/). 